\title{
VIOLÊNCIA E ABUSO SEXUAL NA FAMÍLIA
}

Maria de Fátima Araújo*

\begin{abstract}
RESUMO. Trata-se de relato de experiência de supervisão e atendimento de famílias que sofreram violência intrafamiliar, encaminhadas para atendimento psicológico após denúncia ou suspeita de abuso sexual infantil cometido por parentes próximos. O texto examina essa experiência à luz de reflexões surgidas nessa prática, diante dos conflitos, impasses e dificuldades vividos por profissionais e famílias envolvidos no problema. A abordagem de intervenção aqui proposta tem três características principais: 1) baseia-se no enfoque psicossocial 2) propõe o atendimento familiar conjunto, envolvendo toda a família, inclusive o agressor; e, 3)introduz a perspectiva de gênero, fator historicamente preponderante na construção de relações de violência e dominação-exploração dentro da família.
\end{abstract}

Palavras-chave: violência intrafamiliar; abuso sexual infantil; intervenção.

\section{VIOLENCE AND SEXUAL ABUSE WITHIN THE FAMILY}

\begin{abstract}
This article reports on the experience of supervising and providing care to families who have experienced intrafamily violence and who were referred to psychological care following suspicion or denouncement of child sexual abuse committed by close relatives. It reviews this experience in the light of reflections arising from the practice in view of the conflicts, impasses and difficulties faced by professionals and families concerned. The type of intervention proposed here has three major characteristics: 1) it is based on a psychosocial approach 2) it proposes a family group treatment including the assailant and 3) it introduces the gender perspective, a historically prevailing factor in the construction of violence and domination/exploitation relationships within the family.
\end{abstract}

Key words: intra-family violence, child sexual abuse, intervention.

\section{INTRODUÇÃO}

A preocupação com os dramáticos índices de crescimento da violência e suas diferentes formas de manifestação coloca-se hoje como uma questão crucial para a sociedade brasileira. Inúmeras causas são apontadas como fatores que propiciam o aumento da violência, entre eles as imensas desigualdades econômicas, sociais e culturais, a disseminação das drogas, o desemprego, ou mesmo os efeitos perversos da chamada cultura de massa. Embora esses fatores contribuam para o aumento da violência, por si sós não explicam o fenômeno. Outros fatores estruturais e conjunturais precisam ser considerados na análise, conforme aponta Angelina Peralva (2000), em Violência e Democracia - o paradoxo brasileiro. A autora questiona as análises sociológicas baseadas na relação entre pobreza e desigualdade social para explicar o fenômeno da violência, bem como as explicações que recorrem ao conceito de anomia, para explicar a revolta e o ódio social das camadas pobres diante da impossibilidade de acesso a bens considerados de valor positivo na cultura de massa. Partindo do fato de que o retorno à democracia se caracterizou por um crescimento sem precedentes da violência, Peralva (2000) introduz dois novos ângulos de análise. O primeiro são as transformações ocorridas no plano social e econômico e os efeitos daí

Universidade Estadual Paulista, Campus Assis, Departamento de Psicologia Clínica, Coordenadora do Núcleo de Estudos Violência e Relações de Gênero.

Endereço para correspondência: Av. Dom Antônio, 2100 - Parque Universitário, 19800-000, Assis/SP. E-mail: fatimaraujo@uol.com.br 
decorrentes na produção de novos conflitos urbanos em uma sociedade onde o individualismo de massa e a experiência do risco são características inerentes. $\mathrm{O}$ segundo refere-se à ausência e ineficiência de políticas públicas e instituições encarregadas de garantir a ordem pública e o respeito à cidadania. Gilberto Velho (2000) desenvolve raciocínio semelhante ao relacionar o aumento da violência ao processo de modernização da sociedade brasileira. Tal processo, segundo Velho (2000), foi acompanhado de um esvaziamento de conteúdos culturais e éticos no sistema de relações sociais, agravado pela incapacidade do poder público de gerir e atender às necessidades básicas da população pobre, que, abandonada à própria sorte, teve que desenvolver estratégias de sobrevivência e adaptação à nova realidade.

Todos esses esforços analíticos confirmam a tese da multicausalidade e complexidade dos processos de produção e reprodução da violência na sociedade brasileira. A face mais assustadora desse fenômeno é a banalização da violência, que passa a ser vista como natural, restando aos que são afetados aprender a conviver com ela. È enorme o impacto dessa violência estrutural e conjuntural nas relações interpessoais. Ela afeta profundamente as relações familiares, levando à produção e reprodução de modelos de comportamento violentos no cotidiano social e familiar. Crianças que vivem em situação de violência familiar aprendem a usá-la como forma de vida e têm grande possibilidade de reproduzi-la nos seus relacionamentos, tanto na condição de criança quanto na de jovem ou adulto (Araújo, 1996).

\section{DEFININDO VIOLÊNCIA E INTRODUZINDO A PERSPECTIVA DE GÊNERO}

O tema da violência tornou-se, nas últimas décadas, um vasto campo de estudos de diversas disciplinas, sendo focalizado sob diferentes vertentes analíticas. Neste trabalho adotamos o conceito de violência de Chauí (1985), que define violência não como violação ou transgressão de normas, regras e leis, mas sob dois outros ângulos:

Em primeiro lugar, como conversão de uma diferença e de uma assimetria numa relação hierárquica de desigualdade, com fins de dominação, de exploração e opressão. Em segundo lugar, como a ação que trata um ser humano não como sujeito, mas como coisa. Esta se caracteriza pela inércia, pela passividade e pelo silêncio de modo que, quando a atividade e a fala de outrem são impedidas ou anuladas, há violência (Chauí, 1985 , p. 35)

Para Chauí (1985) a violência é uma relação de forças caracterizada num pólo pela dominação e no outro pela coisificação. O pressuposto dessa definição é a idéia de liberdade de Spinoza:

... a liberdade não é a escolha voluntária ante várias opções mas a capacidade de autodeterminação para pensar, querer, sentir e agir. É autonomia. Não se opõe à necessidade (natural ou social), mas trabalha com ela, opondo-se ao constrangimento e à autoridade. Nessa perspectiva, ser sujeito é construir-se e constituir-se como capaz de autonomia numa relação tal que as coisas e os demais não se ofereçam como determinantes do que somos e fazemos, mas como o campo no qual o que somos e fazemos pode ter a capacidade aumentada ou diminuída, segundo nos submetamos ou não à força e à violência ou sejamos agentes dela (Chaúí,1985 p.36)

Nesse sentido, se tomamos a liberdade como uma capacidade e um direito fundamental do ser humano, podemos dizer que a violência é uma violação do direito de liberdade, do direito de ser sujeito constituinte da própria história. Essa concepção de violência de Chauí (1985) fundamenta nossa compreensão da violência intrafamiliar expressa na forma de abuso sexual infantil, conforme relato de experiência que apresentaremos mais adiante.

$\mathrm{Na}$ literatura corrente os conceitos violência intrafamiliar, violência doméstica e violência contra a mulher são freqüentemente usados para nomear a violência que acontece no espaço doméstico e familiar, atingindo crianças, adolescentes e mulheres (Azevedo \& Guerra, 1993; Dallos \& McLaughlin, 1994; Portugal, 2000; Soares, 1999). Apesar da sobreposição existente entre esses recortes, há especificidades em cada um desses conceitos.

Violência intrafamiliar designa a violência que ocorre na família, envolvendo parentes que vivemo ou não sob o mesmo teto, embora a probabilidade de ocorrência seja maior entre parentes que convivem cotidianamente no mesmo domicílio. A violência doméstica, por sua vez, não se limita à família. Envolve todas as pessoas que convivem no mesmo espaço doméstico, vinculadas ou não por laços de parentesco. E a violência contra a mulher, embora ocorra freqüentemente no espaço doméstico e familiar, não se restringe a ele. É perpetrada por parentes e nãoparentes, dentro e fora do domicílio. 
Saffioti (1997) propõe o uso do termo violência de gênero como um conceito mais amplo, abrangendo vítimas como mulheres, crianças e adolescentes de ambos os sexos. Para essa autora, quando se adota a expressão violência contra a mulher ganha-se espaço para além da violência doméstica, mas perde-se grande parte da violência de gênero contida especificamente nas violações dos direitos de crianças e adolescentes, cometidas não só por homens, mas também por mulheres agressoras. Isso prejudica a aproximação do real, pois as mulheres são grandes espancadoras de crianças, embora raramente pratiquem violência sexual contra crianças - as estatísticas internacionais estimam em torno de 1 a $3 \%$ a proporção desse tipo de agressão. Não obstante, ainda que a mulher perpetre violência contra seus filhos, o homem é o maior agressor físico, pois suas vítimas não são somente seus filhos, mas também sua mulher.

Para Saffioti \& Almeida (1995), o conceito de violência de gênero designa um tipo específico de violência que visa à preservação da organização social de gênero, fundada na hierarquia e desigualdade de lugares sociais sexuais. Segundo essas duas autoras, a violência de gênero tem duas faces: é produzida no interior das relações de poder, objetivando o controle de quem detém a menor parcela de poder, e revela a impotência de quem a perpetra para exercer a exploração-dominação, pelo não-consentimento de quem sofre a violência.

A questão de gênero é um fator preponderante na produção da violência social, interpessoal e familiar. Como destaca Saffiotti (1999), é importante lembrar que a predominância da categoria de gênero não existe de forma abstrata, ao contrário, articula-se com as categorias de classe e raça/etnia. Na escala social do exercício da dominação-exploração por legitimação do poder ou imposição através da violência, o homem adulto, branco e rico tem predominância sobre as mulheres, crianças, pobres e negros.

No exercício da função patriarcal, os homens detêm o poder de determinar a conduta das categorias sociais nomeadas, recebendo autorização ou, pelo menos, tolerância da sociedade para punir o que se lhes apresenta como desvio. Ainda que não haja nenhuma tentativa, por parte das vítimas potenciais, de trilhar caminhos diversos do prescrito pelas normas sociais, a execução do projeto de dominação- exploração da categoria social homens (grifo da autora) exige que sua capacidade de mando seja auxiliada pela violência. Com efeito, a ideologia de gênero é insuficiente para garantir a obediência das vítimas potenciais diante dos ditames do patriarca, tendo este necessidade de fazer uso da violência. Nada impede, embora seja inusitado, que uma mulher pratique violência contra seu marido/companheiro/namorado. As mulheres como categoria social não têm, contudo, um projeto de dominaçãoexploração dos homens. Isso faz uma gigantesca diferença (Saffioti, 2001, p. 115)

No Brasil, a violência intrafamiliar contra mulheres, crianças e adolescentes ainda é um fenômeno social grave, como apontam os inúmeros estudos existentes (Azevedo \& Guerra, 1989 e 1993; Saffioti, 1997; Almeida, 1998). Todas as pesquisas apontam como principal alvo da violência intrafamiliar as mulheres e crianças do sexo feminino. Isso não quer dizer que os meninos não sofram violência: eles sofrem, mas isso ocorre em menor proporção, principalmente quando se trata de abuso sexual infantil dentro da família (Azevedo \& Guerra, 1993; Cohen, 1993; Saffioti, 1997).

A violência intrafamiliar continua acontecendo, apesar de algumas conquistas no campo institucional, político e jurídico ${ }^{1}$. Mantém-se pela impunidade, pela ineficiência de políticas públicas e ineficácia das práticas de intervenção e prevenção. Mantém-se também com a cumplicidade silenciosa dos envolvidos: o silêncio da vítima, cuja palavra é confiscada pelo agressor através de ameaças; o silêncio dos demais parentes não agressores, que fecham os olhos e se omitem de qualquer atitude de proteção da vítima ou de denúncia do agressor; o silêncio dos profissionais que, em nome da ética e do sigilo profissional, se refugiam muitas vezes numa atitude defensiva, negando ou minimizando os efeitos da violência.

\section{VIOLÊNCIA E ABUSO SEXUAL}

O abuso sexual infantil é uma forma de violência que envolve poder, coação e/ou sedução. É uma violência que envolve duas desigualdades básicas: de gênero e geração. $O$ abuso sexual infantil é freqüentemente praticado sem o uso da força física e não deixa marcas visíveis, o que dificulta a sua comprovação, principalmente quando se trata de crianças pequenas. $\mathrm{O}$ abuso sexual pode variar de atos que envolvem contato sexual com ou sem penetração a

\footnotetext{
Vale destacar a mobilização feminista em torno do problema, a criação dos Conselhos Estaduais da Condição Feminina, das Delegacias de Defesa da Mulher e do ECA.
} 
atos em que não há contato sexual, como o voyeurismo e o exibicionismo.

O abuso sexual supõe uma disfunção em três níveis: o poder exercido pelo grande (forte) sobre o pequeno (fraco); a confiança que o pequeno (dependente) tem no grande (protetor); e o uso delinqüente da sexualidade, ou seja, o atentado ao direito que todo indivíduo tem de propriedade sobre seu corpo (Gabel, 1997, p.10)

As pesquisas apontam que, quando se trata de abuso sexual ocorrido no espaço doméstico e familiar, há uma maior predominância do homem como agressor e da mulher como vítima. (Azevedo \& Guerra, 1988; Cohen, 1993; Saffioti, 1997). Os meninos também são vítimas de abuso sexual, mas a incidência maior acontece fora da família, em geral perpetrado por adultos não parentes. Dentre os parentes envolvidos em abuso sexual intrafamiliar, o grande vilão é o pai, conforme aponta pesquisa realizada por Saffioti (1997) no Município de São Paulo sobre abuso incestuoso: 71,5\% dos agressores eram pais biológicos e 11,1\%, padrastos. Portanto, pai e padrasto foram responsáveis por $82,6 \%$ do total de abusos sexuais (Saffioti, 1997, p.183). Essa tendência aparece também em outros estudos (Azevedo \& Guerra, 1993; Cohen, 1993; Furniss, 1993).

O abuso sexual é um fenômeno complexo e difícil de enfrentar por parte de todos os envolvidos. É difícil para a criança e para a família, pois a denúncia do segredo explicita a violência que ocorre dentro da própria família. É difícil também para os profissionais, que muitas vezes não sabem como agir diante do problema.

O abuso sexual infantil é um problema que envolve questões legais de proteção à criança e punição do agressor, e também terapêuticas de atenção à saúde física e mental da criança, tendo em vista as conseqüências psicológicas decorrentes da situação de abuso. Tais conseqüências estão diretamente relacionadas a fatores como: idade da criança e duração do abuso; condições em que ocorre, envolvendo violência ou ameaças; grau de relacionamento com o abusador; e ausência de figuras parentais protetoras.

A revelação do abuso sexual produz uma crise imediata nas famílias e na rede de profissionais. A complexidade dos processos envolvidos exige uma abordagem multidisciplinar que integre os três tipos de intervenção: punitiva, protetora e terapêutica, como propõe Furniss ( 1993). Integrar essas ações de forma a não causar maiores danos à criança, diante da situação de exposição e rupturas desencadeadas pela situação da revelação, é o grande desafio dos profissionais. $\mathrm{O}$ trabalho de atendimento à família, vítimas e agressores, é fundamental. Devido à enorme carga de ansiedade mobilizada nessas situações, freqüientemente a família tenta fugir do atendimento, sendo, muitas vezes, necessário um apoio legal para mantê-la em acompanhamento.

\section{RELATO DE EXPERIÊNCIA}

Este trabalho focaliza um tipo específico de violência intrafamiliar: o abuso sexual infantil praticado por parentes próximos, dentro do próprio lar. Reúne reflexões surgidas na prática de supervisão e atendimento de famílias encaminhadas para atendimento psicológico, após denúncia ou suspeita de abuso sexual infantil. Os atendimentos foram realizados no Projeto Violência de Gênero - projeto de pesquisa-intervenção em desenvolvimento, desde o ano de 2000, no Centro de Pesquisa e Psicologia Aplicada - CPPA da Universidade Estadual Paulista /Unesp/Assis. O referido projeto é voltado para o atendimento da violência familiar e conjugal dentro da perspectiva de gênero, incluindo o agressor no atendimento. Fundamenta-se numa abordagem psicossocial, que busca apreender a complexa rede dos processos envolvidos na dinâmica das relações de violência nos seus diferentes aspectos: psicodinâmicos, éticos, jurídicos, econômicos, sociais e culturais. Tal proposta adota o conceito de gênero como uma categoria analítica, historicamente preponderante na construção de relações de violência, dominação e exploração. Essa mesma abordagem é utilizada no trabalho de supervisão de atendimento de famílias que sofreram violência e abuso sexual, realizado por psicólogos vinculados à rede municipal de saúde (Unidades Básicas de Saúde), de Assis e região, que recorrem ao Núcleo de Estudos Violência e Relações de Gênero, da Unesp de Assis, em busca de orientação. O encaminhamento dessas famílias, tanto para o Projeto Violência de Gênero quanto para a rede de saúde, é feito pelos Conselhos Tutelares e Poder Judiciário com solicitação de atendimento psicológico.

Nos casos de violência intrafamiliar envolvendo abuso sexual infantil atendidos no projeto, $80 \%$ dos agressores eram homens adultos - pai biológico, padrasto e irmão, e as vítimas crianças e adolescentes do sexo feminino. Apenas em $3 \%$ dos casos atendidos as vítimas eram meninos. Nesses casos, o abuso ocorreu fora do domicílio familiar, e os agressores eram homens adultos não parentes, e crianças e 
adolescentes maiores. Embora o abuso sexual intrafamiliar envolvendo meninos também aconteça, no projeto não aparece nenhum caso.

\section{IMPASSES E DIFICULDADES NO ATENDIMENTO DE FAMÍLIAS ABUSIVAS}

$\mathrm{O}$ atendimento do abuso sexual infantil gera muita ansiedade nas equipes de saúde e nas varas da família, por conta das dúvidas levantadas sobre a veracidade ou não da denúncia, e, principalmente, pela resistência das famílias diante da imposição judicial do atendimento. $\mathrm{Na}$ rede pública de assistência, esses casos em geral são submetidos a um "jogo-deempurra" entre os profissionais e as instituições. Isso acontece por uma série de questões. A primeiro é que se trata de uma situação difícil de lidar e a maioria dos profissionais não têm treinamento adequado para isso. Outra é que não há recursos institucionais ${ }^{2}$ para dar apoio às vítimas e/ou profissionais que assumem o risco de levar adiante a denúncia. A terceira questão e que muitas vezes a vítima, diante do dilema de denunciar e enfrentar as conseqüências do seu ato, prefere silenciar ou mesmo retirar a denúncia já feita, diante da pressão e da falta de apoio familiar, deixando os profissionais envolvidos desapontados e impotentes diante da situação.

A família, na forma como a conhecemos hoje, é uma instituição social básica, fundamental para a formação do indivíduo. Cabe ao pais zelar pelo desenvolvimento físico e emocional de seus filhos, provendo às suas necessidades materiais e afetivas e garantindo-lhes proteção e segurança. Assim sendo, podemos dizer que há violência intrafamiliar contra crianças e adolescentes quando os pais utilizam o

\footnotetext{
${ }^{2}$ No Brasil não há um aparato social e institucional para acolher as famílias vitimadas. No máximo há casasabrigo, que em geral funcionam precariamente, e, muitas vezes, ao acolherem a criança causam-lhe um dano maior ao separá-la da família (a criança se sente punida e não protegida). Além disso, no plano jurídico, a burocratização dificulta a punição do agressor. Sendo a violência familiar um "crime privado", depende da representação da vítima, que, muitas vezes, não efetua a queixa. É verdade que nos últimos anos cresceu a preocupação do governo com a questão do abuso sexual infantil. A criação de "Pactos Nacionais e Regionais contra o abuso sexual e exploração infantil" bem como a criação do Projeto Sentinela, em implantação em alguns municípios brasileiros (inclusive em Assis), são tentativas de enfrentamento que, se não resolvem, pelo menos dão maior visibilidade ao problema.
}

poder que lhes conferem esses papéis para fins de dominação e exploração, para satisfazer seus desejos e necessidades pessoais. Instaura-se assim uma confusão entre papéis e funções, principalmente no caso do abuso sexual, quando tais atos são acompanhados de cenas de sedução e carinho que mascaram a violência e o abuso. Tais comportamentos deixam a criança confusa e, dependendo do tipo de relação que mantém com o agressor, ela oscila entre calar ou denunciar tais atos praticados por alguém que, por obrigação, deveria lhe dispensar cuidado e proteção.

Quando o autor do abuso sexual infantil é o pai biológico, configura-se uma situação incestuosa, que se dá fora do mito do Édipo, mas com implicações também muito trágicas. O pai abusador, ao impor a lei do seu desejo, transgride a lei cultural que proíbe o incesto (Lévi-Strauss, 1976), trai a confiança da criança e se aproveita da sua vulnerabilidade e imaturidade. Garante o silêncio da vítima muitas vezes com promessas, cumplicidade ou mesmo ameaças, e, freqüentemente, se beneficia da conivência ou cegueira da mãe e dos outros membros da família. A criança vive uma situação traumática e conflituosa, permeada por diferentes sentimentos onde se misturam medo, raiva, prazer, culpa e desamparo. Tem raiva da mãe por não protegê-la e tem medo de contar, com receio de que não acreditem nela ou a considerem culpada.

A mãe, por sua vez, também vive uma situação de muita confusão e ambigüidade diante da suspeita ou constatação de que o marido ou companheiro abusa sexualmente da filha. Freqüentemente nega os indícios, denega suas percepções, recusa-se a aceitar a realidade da traição do marido. Vive sentimentos ambivalentes em relação à filha: ao mesmo tempo que sente raiva e ciúme, sente-se culpada por não protegê-la. Na verdade, ela também é vítima, vítima secundária ${ }^{3}$, da violência familiar. Negar, desmentir a filha ou culpá-la pela sedução é uma forma de suportar o impacto da violência, da desilusão e da frustração diante da ameaça de desmoronamento da unidade familiar e conjugal. Pode acontecer também estar a negação da mãe relacionada com uma cumplicidade silenciosa, muito freqüente em casais com conflitos sexuais, onde a criança ocupa um lugar (função sexual) que não é dela, amenizando assim o conflito conjugal. Em qualquer das situações, o desmentido materno, a afirmação de que nada aconteceu, é o pior que pode acontecer a uma criança que denuncia o abuso sexual.

\footnotetext{
Expressão usada pela autora americana Carol Ann Hooper (conforme citado por Fuks, 1998).
} 
Mulheres que sofreram abuso sexual na infância tornam-se mais vulneráveis para estabelecer relações com homens abusivos e, consequientemente, mostramse menos capazes de proteger suas próprias filhas do abuso sexual. A repetição do abuso sexual com suas filhas é estatisticamente significativa (Fuks, 1998; Hirigoyen, 2000; Soares, 1999).

Essa repetição se observa também na história de vida de homens abusadores (Miller, 1994; Islas, 2000; Kaufman Jr., 1994 e Gramm, 1997), muito freqüentemente eles foram vítimas de abuso na infância. Vale lembrar que, apesar da incidência da repetição ser um fator muito presente na história de vida de homens e mulheres que sofreram abuso sexual na infância, não há um determinismo linear envolvendo esses fatos. São muitos os processos de subjetivação produzidos no percurso de elaboração dessas experiências.

No entanto, em muitas famílias podemos observar a reprodução de uma cultura familiar onde a violência e o abuso sexual acontecem e se mantêm protegidos pela lei do silêncio. Esse segredo familiar pode percorrer várias gerações sem ser denunciado. Há um mito em torno dele, não se fala, mas todos sabem ou parecem saber da sua existência, mesmo que ignorem o conteúdo; mas silenciam, num pacto inconsciente com o agressor ou em nome de uma pseudo-harmonia familiar. Nas famílias incestuosas a lei de preservação do segredo familiar prevalece sobre a lei moral e social. É por isso que é tão difícil a denúncia e a sua confirmação. A criança ou adolescente vitimada reluta em denunciar o agressor (pai, padrasto ou irmão, pois corre o risco de ser desacreditada, insultada, punida ou até afastada de casa sob a acusação de destruir a harmonia e a unidade familiar.

\section{PROPOSTA DE INTERVENÇÃO: ATENDIMENTO FAMILIAR CONJUNTO INCLUINDO O AGRESSOR}

O que fazer então? Como intervir nessas situações? Sabe-se das consequiências traumáticas na vida de uma criança ou adolescente submetidos a situações de violência e abuso sexual. Sabe-se também que só trabalhar com a criança não é suficiente, porquanto é a família que precisa de ajuda. Mas como vencer a rigidez do sistema familiar e a resistência à ajuda? Como vencer a cegueira materna, como romper o pacto silencioso entre os demais membros da família em torno do segredo familiar que protege o autor do abuso sexual infantil?

A indicação terapêutica mais adequada para os casos de abuso sexual infantil intrafamiliar é a terapia do grupo familiar ${ }^{4}$, envolvendo todos os membros da família, principalmente o agressor ${ }^{5}$. A dificuldade está em transformar essa indicação em demanda. O trabalho começa com a discussão do problema denúncia ou suspeita do abuso - e suas implicações na dinâmica familiar. Explicita-se que o problema não é apenas da criança vitimada, mas de todos eles, e como tal, precisa ser pensado e trabalhado em conjunto.

Partindo do princípio de que os problemas da família dizem respeito a todos e como tal devem ser trabalhados no seio da própria família, nossa proposta é trabalhar o grupo familiar no enfoque operativo, como propõe Pichon-Rivière (1994), procurando criar um espaço de acolhimento e reflexão para a família pensar sobre o problema e buscar soluções mais criativas para resolver o conflito e não negá-lo.

Esta tarefa implica redefinir papéis, funções e responsabilidades de cada um, rompendo a cumplicidade silenciosa e restabelecendo a rede de comunicação. Isso possibilita uma contenção da ansiedade e desbloqueio da espontaneidade para que o grupo possa desenvolver uma "adaptação ativa" à realidade. Como diz Pichon-Rivière,

um grupo obtém uma adaptação ativa à realidade quando adquire insight, quando se torna consciente de certos aspectos de sua estrutura e dinâmica, quando cada sujeito conhece e desempenha seu papel específico e o grupo se abre à comunicação e ao processo de aprendizagem e interação com o meio (Pichon-Riviére, 1994, p. 53).

Esta proposta de atendimento familiar nos moldes de um grupo operativo desenvolve-se dentro de enfoque psicossocial, que busca apreender os diferentes aspectos envolvidos : psicológicos (conscientes e inconscientes), interacionais, sociais, econômicos e culturais envolvidos na história da família e sua contextualização atual. A perspectiva de gênero é introduzida aqui como um fator importante para entender as relações de poder dentro da família que transformam diferenças (de gênero ou geração) em desigualdades com fins de dominação-exploração. Parte-se sempre da singularidade da família, identificando suas crenças, valores, resistências,

4 Vale lembrar que a terapia familiar não substitui o trabalho do judiciário na apuração e punição do delito e também não exclui a necessidade de atendimento individual da criança, do agressor ou mesmo da mãe no processo de restruturação da família.

5 O trabalho com a família abusiva, incluindo o agressor, é uma prática também muito usada por terapeutas sistêmicos (ver Hamon, 1997 e Madanes, 1997) 
capacidade de mudança e potencial criativo. Inicialmente faz-se uma avaliação de como ela se apresenta no momento, como cada um de seus membros pensa, sente e se relaciona com o problema, e de que recursos dispõe para transformar a realidade familiar. A partir daí vão se construindo as estratégias de intervenção, que, muitas vezes, exigem do terapeuta "desconstruções" de suas próprias crenças, valores morais e práticas terapêuticas já instituídas. Esse é, por excelência, um campo de criatividade onde o saber/fazer terapêutico é constantemente reinventado, recriado e reconstruído, de forma a possibilitar à família uma melhor compreensão da sua realidade.

Não é uma tarefa fácil para o grupo familiar, e muito menos para os terapeutas, que, na maioria das vezes, preferem atender os membros da família individualmente. Temos visto como é comum na rede de saúde, mesmo com famílias nas quais mais de uma criança é vítima de abuso sexual, cada membro da equipe se responsabilizar pelo atendimento individual de um membro da família (vítimas e agressores) e, no máximo, a equipe de terapeutas se reunir para discutir $\mathrm{o}$ caso. $\mathrm{O}$ atendimento individual do agressor ou da criança que sofreu abuso sexual infantil, embora necessário, é de pouca valia em termos de transformação da realidade familiar, pois se restringe aos diretamente envolvidos. Essa conduta, de certa forma, mantém o segredo familiar no âmbito dos seus principais protagonistas - a criança (vítima primária), a mãe (vítima secundária) e o autor do abuso, enquanto o restante da família pode continuar partilhando o segredo a distância, sem se envolver diretamente.

$\mathrm{O}$ atendimento da família na abordagem aqui proposta busca romper o pacto silencioso que envolve o abuso, amplia o conflito familiar, explicita o funcionamento incestuoso e a cumplicidade inconsciente de seus membros. É um momento difícil para todos, mobiliza sentimentos ambivalentes de amor e ódio, de proteção e rejeição, de negação e enfrentamento da realidade. $\mathrm{O}$ trabalho passa por várias etapas e seu desenvolvimento depende do ponto de partida: suspeita ou denúncia confirmada? O agressor admite o abuso? A mãe desmente ou acredita na denúncia da filha? Como reagem os outros membros da família? admitem sua omissão/participação? O trabalho pode começar, por exemplo, explicitando o que se considera violência ou abuso sexual infantil, ou discutindo as fronteiras, funções e papéis familiares, diferenças de gênero e geração, e relações de poder. Ou ainda, pode começar focalizando o impacto da suspeita ou denúncia do abuso sexual no funcionamento atual da família.
Admitindo-se ou não, há um fato novo que desestabilizou a família e explicitou a necessidade de intervenção. Qualquer um dos caminhos escolhidos vai exigir muita habilidade do terapeuta para lidar com a resistência familiar, principalmente do agressor, para transformar a indicação da terapia familiar numa demanda da própria família.

Assim como a família, o terapeuta também é muito mobilizado emocionalmente durante o processo. Precisa estar atento às suas defesas, resistências e processos transferenciais e contratransferenciais que naturalmente surgem. E, mais ainda, precisa estar atento para não se tornar refém do dilema familiar, principalmente quando a suspeita não é confirmada $\mathrm{e}$ prevalece a dúvida. Seu papel não é investigar para apurar a veracidade da denúncia. Embora isso seja importante, e necessário, para o desenvolvimento do trabalho com a família, seu ponto de partida é o próprio fato de existir uma suspeita ou denúncia que explicitou o conflito familiar. Muitas vezes prevalece a dúvida, a denúncia não se confirma, a queixa é retirada e o agressor é apenas advertido. Isso dificulta o trabalho com a família, que em geral abandona o atendimento, deixando o terapeuta frustrado diante da necessidade de intervenção e do seu próprio desejo de ajudar.

São muitos os processos envolvidos na dinâmica de famílias abusivas. Nas famílias objeto deste relato, dois fatores se destacam: a questão de gênero e ofator econômico. A dominação masculina e a submissão feminina, cristalizadas, naturalizam a produção e repetição de comportamentos abusivos por parte do homem detentor do poder de pai, provedor material e chefe da família. Ao se colocarem na condição de inferioridade, as próprias mulheres delegam poderes a seus maridos, companheiros e pais. E é nesse lugar que eles reproduzem comportamentos abusivos. Denunciar isso implica questionar esses próprios lugares, ou seja, desconstruir essa relação de poder desigual, que não é natural, mas sim construída socialmente, conforme apontam os estudos de gênero (Saffioti, 1999; Scott, 1990).

$\mathrm{O}$ ato da denúncia do abuso sexual configura-se como um questionamento desses lugares de poder, legitimados pela dominação masculina. Levar adiante a denúncia, exigir a punição do agressor e investir na mudança das relações abusivas é algo mais complexo e esbarra, muitas vezes, em impedimentos concretos, onde o fator econômico tem um enorme peso, principalmente quando o homem abusador é o único provedor material da família.

$\mathrm{Na}$ ausência de um entorno social, familiar, institucional e jurídico que ampare a família após a 
denúncia, a mesma se vê sob ameaça do total abandono social e privação econômica. Isso se acentua quando as crianças são pequenas, a mãe não trabalha e o sustento da família vem do trabalho do pai que não tem emprego fixo, o que poderia garantir judicialmente o sustento da família. A retirada da denúncia frequientemente acontece após ameaça do pai de abandonar o trabalho e a família que não conta com nenhuma ajuda externa, seja do poder público, seja da comunidade seja de outros parentes. Nesses casos, a violência social se sobrepõe à violência intrafamiliar. Daí a importância do trabalho multidisciplinar que envolva ações integradas de cuidado e atenção à saúde, punição do agressor e proteção às crianças e famílias submetidas a situações de violência e abuso sexual. Para garantir a continuidade do atendimento familiar em geral é necessário que o poder público institua a obrigatoriedade do atendimento, incluindo o agressor, como medida socioeducativa assim como, nos casos de punição e afastamento do agressor do domicílio familiar, é necessário dar um amparo legal e material à família. Criar dispositivos que integrem todas essas ações de forma eficiente e eficaz é o grande desafio do poder público, da sociedade civil e dos profissionais que lidam com essa realidade.

\section{REFERÊNCIAS BIBLIOGRÁFICAS}

Almeida, S.S. (1998). Femicídio: Algemas invisíveis do público-privado. São Paulo: Revinter.

Araújo, M. de F. (1996). Atendimento a mulheres e famílias vítimas de violência doméstica. Perfil. 9, 07-17.

Araújo, M. de F. (2001). Violência Familiar: o dilema entre a denúncia e o silêncio. Como Intervir? Em Anais do I Congresso de Psicologia Clínica (pp. 57-61). Universidade Presbiteriana Mackenzie, São Paulo, SP.

Azevedo, M.A. \& Guerra, V.N. (1988). Pele de asno não é só estória... um estudo sobre a vitimização sexual de crianças $e$ adolescentes em família. São Paulo: Editora Roca.

Azevedo, M.A. \& Guerra, V.N. (1989). Crianças Vitimizadas: A síndrome do pequeno poder. São Paulo: Iglu Editora.

Azevedo, M.A. \& Guerra, V.N. (1993). Incesto ordinário: a vitimização sexual doméstica da mulher-criança e suas conseqüências psicológicas. Em M.A. Azevedo \& V.N. Guerra (Orgs.), Infância e Violência Doméstica: fronteiras do conhecimento (pp 195-208). São Paulo: Cortez.

Chauí, M. (1985). Participando do debate sobre mulher e violência. Em Perspectivas Antropológicas da Mulher (pp. 25-62). Rio de Janeiro: Zahar.

Cohen, C. (1993). O incesto. Em M.A. Azevedo \& V.N. Guerra (Orgs.), Infância e Violência Doméstica: fronteiras do conhecimento (pp. 211-225). São Paulo: Cortez.

Dallos, R. \& McLaughlin, E. (1994). Social Problems and the Family. London: Sage.

Fuks, L.B. (1998). Abuso sexual de crianças na família. Percurso. 20 (1), 120-126.
Furniss, T. (1993). Abuso sexual da criança: Uma abordagem multidisciplinar. (M.A.V. Veronese, Trad.) Porto Alegre: Artes Médicas. (Trabalho original publicado em 1991).

Gabel, M. (1997). Crianças vítimas de abuso sexual. (S. Goldfeder \& M.C.C. Gomes, Trad.) São Paulo: Summus Editorial. (Trabalho original publicado em 1992).

Gramm, L. (1997). Arrependimento e Reparação em Casos de Abuso Sexual. Em C. Madanes (Org.), Sexo, Amor $e$ Violência (pp. 74-89). (M.C.E. Lopes \& S.M.C. Machado, Trad.) São Paulo: Ed. Psy. (Trabalho original publicado em 1990).

Hamon, H. (1997). Abordagem sistêmica do tratamento sóciojudiciário da criança vítima de abusos sexuais intrafamiliares. Em M. Gabel (Org.), Crianças vítimas de abuso sexual (pp.174-187). (S. Goldfeder \& M.C.C. Gomes, Trad.) São Paulo: Summus Editorial. (Trabalho original publicado em 1992).

Hirigoyen, M.F. (2000). Assédio Moral: A violência perversa do cotidiano. (M.H. Kühner, Trad.) São Paulo: Bertrand Brasil. (Trabalho original publicado em 1998).

Islas, F.C. (2000). Ajudando os homens a superar o comportamento violento em relação às mulheres. Em A.R. Morrison \& M.L. Biehl (Orgs.), A família Ameaçada: violência doméstica nas Américas (pp. 149-152). (G.B. Soares, Trad.) Rio de Janeiro: Ed. FGV. (Trabalho original publicado em 2000).

Kaufman Jr., G. (1994). O misterioso desaparecimento das mulheres espancadas dos consultórios de terapeutas de família: privilégio masculino em conluio com a violência dos homens. Em E. Imber-Black (Org.), Os Segredos na Família e na Terapia Familiar (pp. 200-215). ( D. Batista, Trad.) Porto Alegre: Artes Médicas. (Trabalho original publicado em 1991).

Lèvi-Strauss, C. (1976). As estruturas elementares do parentesco. (M Ferreira, Trad.) Petrópolis: Vozes. (Trabalho original publicado em 1967).

Madanes, C. (1997). Sexo, Amor e Violência. (M.C.E. Lopes \& S.M.C. Machado, Trad.) São Paulo: Ed. Psy. (Trabalho original publicado em 1990).

Miller, D. (1994). Incesto: o centro da escuridão. Em E. ImberBlack (Org.), Os Segredos na Família e na Terapia Familiar (pp. 185-199). (D. Batista, Trad.) Porto Alegre: Artes Médicas. (Trabalho original publicado em 1991).

Olarte, E.G. \& Llosa, P.G. (2000). A pobreza pode causar violência doméstica? Algumas respostas de Lima. Em A.R. Morrison \& M.L. Biehl (Orgs.), A Família Ameaçada: violência doméstica nas Américas (pp. 49-61). (G.B. Soares, Trad.) Rio de janeiro: Ed. FGV. (Trabalho original publicado em 2000).

Peralva, A. (2000). Violência e Democracia: O paradoxo brasileiro. São Paulo: Paz e Terra.

Pichon-Riviére, E. (1994). O processo grupal. (M.A.F. Velloso, Trad.) São Paulo: Martins Fontes. (Trabalho original publicado em 1980).

Portugal, S. (2000). Globalização e Violência Doméstica. Revista Crítica de Ciências Sociais. 57/58, 231-258.

Sabourin, P. ( 1997). Por que a terapia familiar em face do incesto? Em M. Gabel (Org.), Crianças vítimas de abuso sexual (pp. 164-173). (S. Goldfeder \& M.C.C. Gomes, 
Trad.) São Paulo: Summus Editorial. (Trabalho original publicado em 1992).

Saffioti, H.I.B. (1993). Circuito cerrado: abuso sexual incestuoso. Em Vigiladas y Castigadas. Lima, Peru: CLADEM.

Saffioti, H.I.B. (1997). No Fio da Navalha: Violência Contra Crianças e Adolescentes no Brasil Atual. Em F.R. Madeira (Org.), Quem Mandou Nascer Mulher? (pp. 134-211). São Paulo: Editora Rosa dos Tempos.

Saffioti, H.I.B. (1999). O Estatuto teórico da violência de gênero. Em J.V.T. dos Santos (Org.), Violência em tempo de globalização (pp.142-163). São Paulo: Hucitec.

Saffioti, H.I.B. (2001). Contribuições feministas para o estudo da violência de gênero. Cadernos Pagu. (16), 115-136.

Saffioti, H.I.B. \& Almeida, S. S. (1995). Violência de Gênero: poder e impotência. Rio de Janeiro: Revinter.
Scott, J. (1990). Gênero: uma categoria útil de análise histórica. Revista Educação e Realidade. 16 (2), 5-22.

Soares, B.M. (1999). Mulheres Invisíveis: Violência Conjugal e novas políticas de segurança. Rio de Janeiro: Civilização Brasileira.

Velho, G. (2000). Violência, reciprocidade e desigualdade: uma perspectiva antropológica. Em G. Velho \& M. Alvito (Orgs.), Cidadania e Violência (pp. 11-25 ). Rio de Janeiro: Ed. UFRJ/FGV. 